\title{
OPTIMAL CONTROLLER DESIGN FOR TWO ARM MANIPULATORS USING QUANTITATIVE FEEDBACK THEORY METHOD
}

\author{
Mohammad Reza Gharib \\ MSc Student, Mechanic Engineering \\ Mech. Eng. Dept, Ferdowsi Univ. IRAN \\ mech_gharib@yahoo.com
}

\author{
Amir Ali Amiri Moghadam \\ MSc Student, Mechanic Engineering \\ Mech. Eng. Dept, Ferdowsi Univ. IRAN \\ amirali1211982@yahoo.com
}

\author{
Majid Moavenian \\ Assistant Professor \\ Ferdowsi Univ. IRAN \\ majidmoaven@yahoo.com
}

\begin{abstract}
In this paper, a practical method to design a robust controller for a two-arm manipulator using Quantitative Feedback Theory (QFT) is proposed. As the two arm manipulators have, multivariable nonlinear transfer function, implementation of QFT technique requires first to convert its nonlinear plant into family of linear and uncertain plant sets, then an optimal robust controller will be designed for each set. In order to illustrate the utility of our algorithm we present the application of it to a two degree of freedom robot arm manipulator. An optimal robust controller is designed for tracking problem. At the end nonlinear simulation for tracking problem in an arbitrary path has been carried out which indicates successful design of controllers and prefilters.
\end{abstract}

\section{KEYWORDS}

Two Arm Manipulators, QFT, Loop Shaping, Dynamic Equations

\section{INTRODUCTION}

The purpose of a robot is to control the movement of its gripper to perform various industrial jobs such as assembly, material handling, painting, and welding [1]. Robot manipulators have complex nonlinear dynamics that might make accurate and robust control difficult. Fortunately, robots are in the class of Lagrangian dynamical systems, so that they have several extremely nice physical properties that make their control straight forward [2]. There are several methods for controlling of a robot such as: classical joint control, digital control, adaptive control, robust control, learning control, force control, and teleoperation. In this paper we consider the two arm manipulators as a two degree of freedom nonlinear multiple-input multiple-output (MIMO) system and as a controlling technique Quantitative Feedback Theory (QFT) will be used.

There are many practical systems that have high uncertainty in open-loop transfer functions which makes it very difficult to have suitable stability margins and good performance in command following problems for the closed-loop system. Therefore a single fixed controller in such systems is found among "robust control" family.

Quantitative Feedback Theory (QFT) is a robust feedback control system design technique introduced by Horowitz (1963, 1979), which 
allows direct design to closed-loop robust performance and stability specifications.

Consider the feedback system shown in diagram Fig.1. This system has two-degrees of freedom structure. In this diagram $\mathrm{p}(\mathrm{s})$ is uncertain plant belongs to a set $p(s) \in\{p(s, \alpha) ; \alpha \in p\}$ where $\alpha$ is the vector of uncertain parameters for uncertainty structured of $\mathrm{p}(\mathrm{s}), \mathrm{G}(\mathrm{s})$ is the fixed structure feedback controller and $F(s)$ is the prefilter. [3], [4].

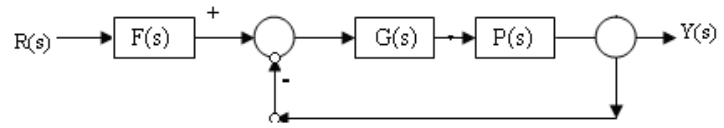

Figure 1 Structure of a Two Degrees of Freedom System

\section{DYNAMIC EQUATIONS OF THE ROBOTIC MANIPULATOR}

Fig.2 depicts a two degree of freedom robot, where $m_{1}, m_{2}$ are the masses of links 1,2 and $l_{1}$, $l_{2}$ are the length of the links 1,2 respectively. The dynamic equation of the robotic manipulator is [5].

$$
M(q) \ddot{q}+C(q, \dot{q}) \dot{q}+G(q)=\tau
$$

$M(q)=\left[\begin{array}{cc}\left(\frac{1}{3} m_{1}+m_{2}\right) l_{1}^{2}+\frac{1}{3} m_{2} l_{2}^{2}+m_{2} l_{1} l_{2} \cos q_{2} & \frac{1}{3} m_{2} l_{2}^{2}+\frac{1}{2} m_{2} l_{1} l_{2} \cos q_{2} \\ \frac{1}{3} m_{2} l_{2}^{2}+\frac{1}{2} m_{2} l_{1} l_{2} \cos q_{2} & \frac{1}{3} m_{2} l_{2}^{2}\end{array}\right]$

$C(q, \dot{q})$ is a $2 \times 2$ matrix of coriolis and centrifugal forces that can be described as:

$$
C(q, \dot{q})=\left[\begin{array}{cc}
-\frac{1}{2} m_{2} l_{1} l_{2}\left(2 \dot{q}_{2}\right) & -\frac{1}{2} m_{2} l_{1} l_{2} \dot{q}_{2} \sin q_{2} \\
\frac{1}{2} m_{2} l_{1} l_{2} \dot{q}_{1} \sin q_{2} & 0
\end{array}\right]
$$

And $G(q)$ is a $2 \times 1$ gravity vector that can be represented as:

$G(q)=\left[\begin{array}{c}\left(\frac{1}{2} m_{1}+m_{2}\right) g l_{1} \cos q_{1}+\frac{1}{2} m_{2} g l_{2} \cos \left(q_{1}+q_{2}\right) \\ \frac{1}{2} m_{2} g l_{2} \cos \left(q_{1}+q_{2}\right)\end{array}\right]$

Where g represents gravity acceleration constant.
The following numerical values are chosen for the robot manipulator

$$
(\mathrm{m} 1=2 \mathrm{~kg}, \mathrm{~m} 2=3 \mathrm{~kg}, \mathrm{~L} 1=0.4 \mathrm{~m} \text { and } \mathrm{L} 2=0.6 \mathrm{~m})
$$

So, dynamic equations of the robot can be derived as follows:

$$
\left\{\begin{array}{l}
\tau_{1}=\left(0.9467+0.72 \cos \left(q_{2}\right)\right) \ddot{q}_{1}+ \\
\left(0.36+0.36 \cos \left(q_{2}\right)\right) \ddot{q}_{2}-0.72 \dot{q}_{1} \dot{q}_{2}- \\
0.36 \dot{q}_{2}^{2} \sin \left(q_{2}\right)+15.68 \cos \left(q_{1}\right)+ \\
8.82 \cos \left(q_{1}+q_{2}\right) \\
\tau_{2}=\left(0.36+0.36 \cos \left(q_{2}\right)\right) \ddot{q}_{1}+0.36 \ddot{q}_{2}+ \\
0.36 \dot{q}_{1}^{2} \sin \left(q_{2}\right)+8.82 \cos \left(q_{1}+q_{2}\right)
\end{array}\right.
$$

Block diagram representation of the above equations which simulates nonlinear multivariable dynamics of robot in Matlab is show in Fig 2.

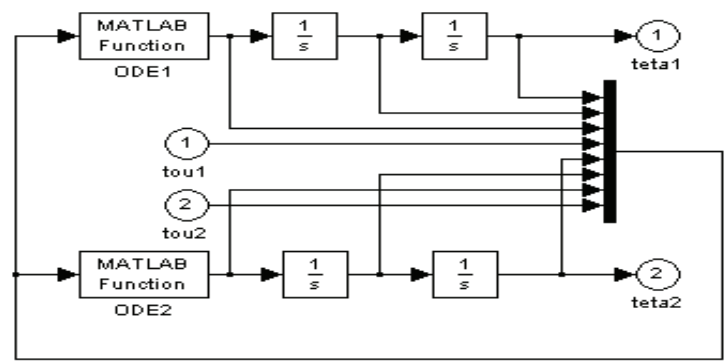

Figure 2 Simulation of Robot Dynamic in Matlab

\section{DESIGN OF QFT CONTROLLER FOR NONLINEAR SYSTEMS}

\subsection{Linearization}

In QFT method, the nonlinear plant is converted to family of linear and uncertain processes. In this paper a simple new method is implemented to apply the above conversion.

Angular velocity, acceleration and required torque for different trajectories can be calculated, simulating the nonlinear model [7], based on these data equivalent linear plant will be derived for each arm as below:

In result linearized transfer function for each arm can be obtained as follows: 
$P_{i}=\frac{1}{s\left(J_{\text {eff }} \cdot s+C_{\text {eff }}\right)} \quad \mathrm{i}=1,2$

\subsection{Template Generation}

Figs.3, 4 show plant uncertainty in Nichols chart for each arm. The linear uncertain plant transfer functions of manipulator can be modeled as below:

1) Arm one $P_{1}=\frac{1}{s\left(J_{\text {eff }} . s+C_{\text {eff }}\right)}$

$\mathrm{J}_{\text {eff }}=[5.3838,7.3716]$

$\mathrm{C}_{\text {eff }}=[27.906155 .7397]$

2) Arm two $P_{2}=\frac{1}{s\left(J_{e f f} . s+C_{e f f}\right)}$

$\mathrm{J}_{\text {eff }}=[3.12584 .1913]$

$\mathrm{C}_{\text {eff }}=[-.3417 \quad 17.4859]$

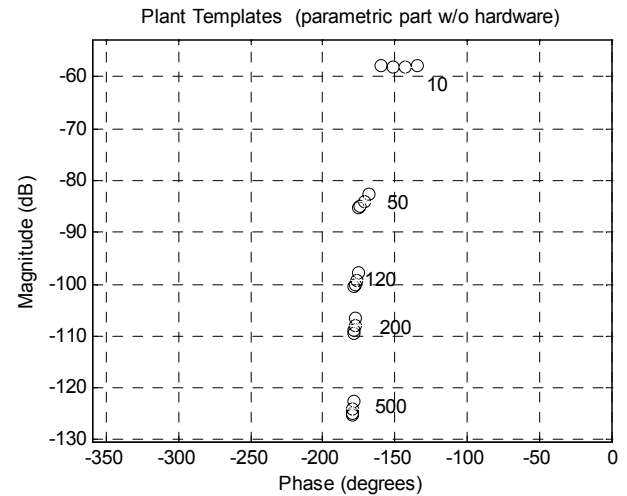

Figure 3 Uncertainty Templates for Arm 1

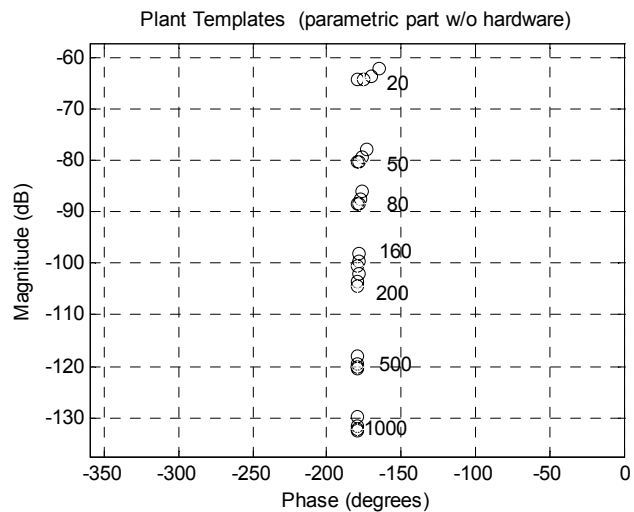

Figure 4 Uncertainty Templates for Arm 2

\subsection{Tracking Problem}

The overshoot and the settling time specifications $\left(\mathrm{M}_{\mathrm{p}}=5 \%\right)$ and $\left(\mathrm{T}_{\mathrm{S}}=0.05 \mathrm{~s}\right)$ respectively are given in the form of upper and lower bounds in frequency domain, usually based on simple second-order models to represent the status of damped condition .Fig 5, 6. [5]

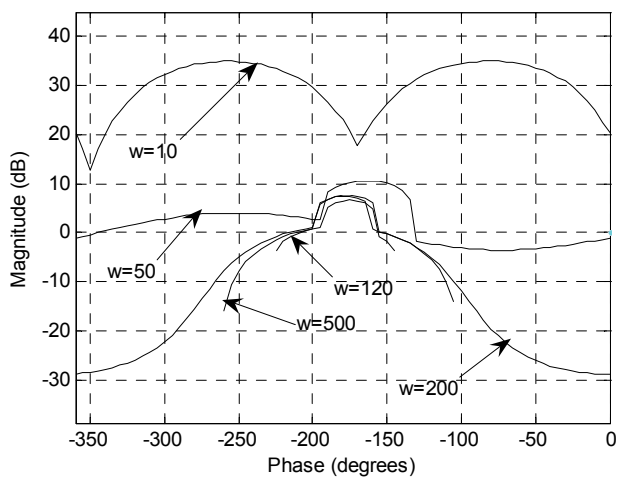

Figure 5 Robust Tracking Bounds for Arm 1

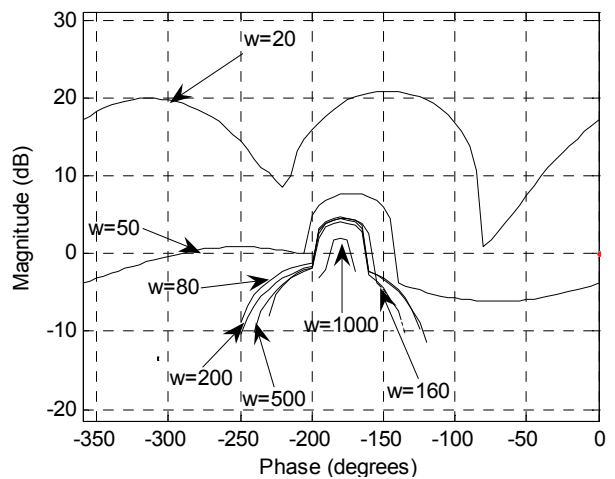

Figure 6 Robust Tracking Bounds for Arm 2

\subsection{Robust Margins}

The following two conditions to achieve robust stability are:

First, stability of the nominal system which means: the Nichols chart envelope should not intersect the critical point $q\left(-180^{\circ}, 0 d B\right)$. [4]

Second, magnitude constraint condition which means: placing a magnitude constraint on the complementary sensitivity function. 
$\left|\frac{1}{1+1}(j \omega)\right|<1.05$ for each arm. Fig. 7, 8

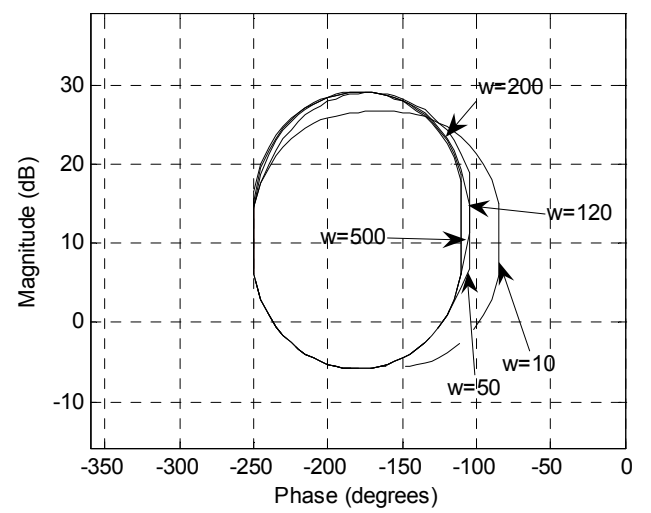

Figure 7 Robust Margins Bounds for Arm 1

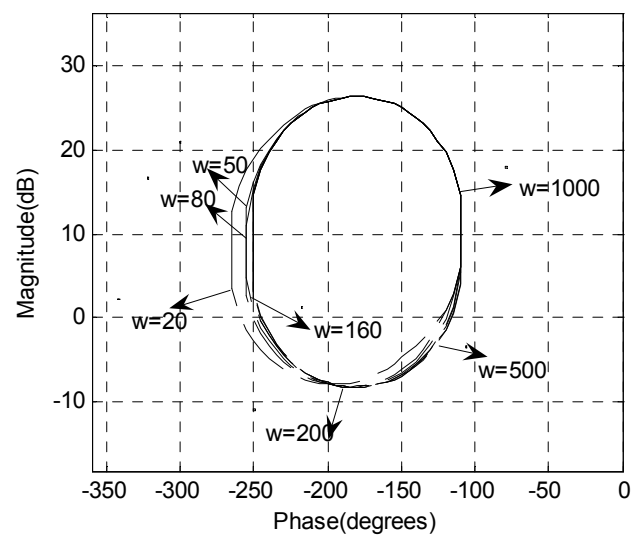

Figure 8 Robust Margins Bounds for Arm 2

\subsection{Loop and Pre-Filter Shaping}

By using the elements of the QFT toolbox we design the controller so that the open loop transfer function exactly lies on its robust performance bounds and does not penetrate the U-contour at all frequency values $\left(\omega_{i}\right)$.Fig. 9,10 . The design of pre-filter guarantees the satisfaction of tracking specification. In Figs. 11, 12 pre-filter shaping of open loop transfer function for each arm is shown. So the optimal controller and pre-filter are designed and given as below:

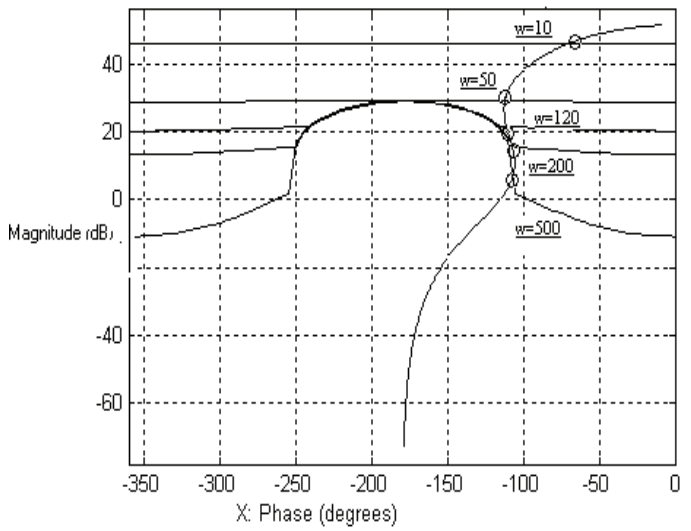

Figure 9 Loop-Shaping in Nichols Chart for Arm 1

$$
\mathrm{G}(\mathrm{s})=238.33 \frac{\mathrm{s}(\mathrm{s}+77.58)}{\left(\frac{\mathrm{s}}{26.76}+1\right)\left(\frac{\mathrm{s}}{2213}+1\right)}
$$

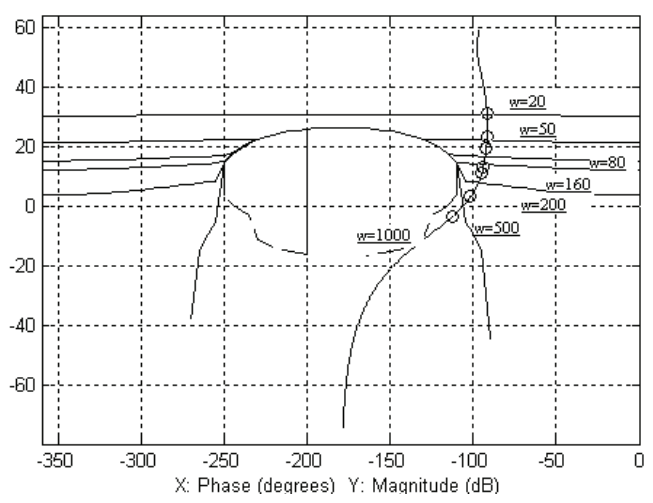

Figure 10 Loop-Shaping in Nichols Chart for Arm 2

$$
G(s)=3033.3 \frac{(s+2.012)}{\left(\frac{s}{2444}+1\right)}
$$




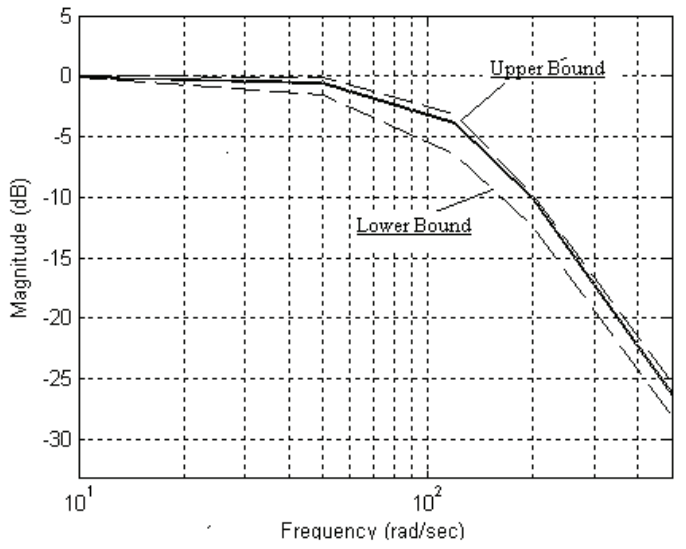

Figure 11 Pre-Filter Shaping in Nichols Chart for Arm 1

$\mathrm{F}(\mathrm{s})=\frac{138.1^{2}\left(\frac{\mathrm{s}}{204.3}+1\right)}{\left(\frac{\mathrm{s}}{122.1}+1\right)\left(\mathrm{s}^{2}+207.15 \mathrm{~s}+138.1^{2}\right)}$

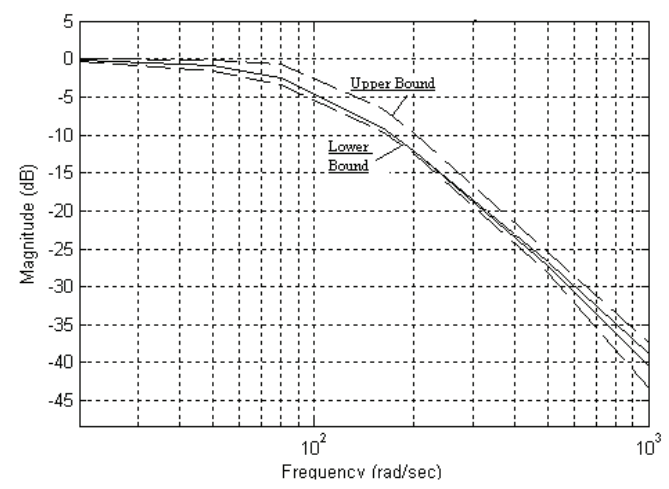

Figure 12 Pre-Filter Shaping in Nichols Chart for Arm 2

$\mathrm{F}(\mathrm{s})=\frac{107.5^{2}\left(\frac{\mathrm{s}}{1542}+1\right)}{\left(\mathrm{s}^{2}+181.1 \mathrm{~s}+107.5^{2}\right)}$

\subsection{Analysis of Design}

The time domain closed loop response of each arm including controller and pre-filter is shown in Figure 13 and 14 respectively which indicates the design is accurate.

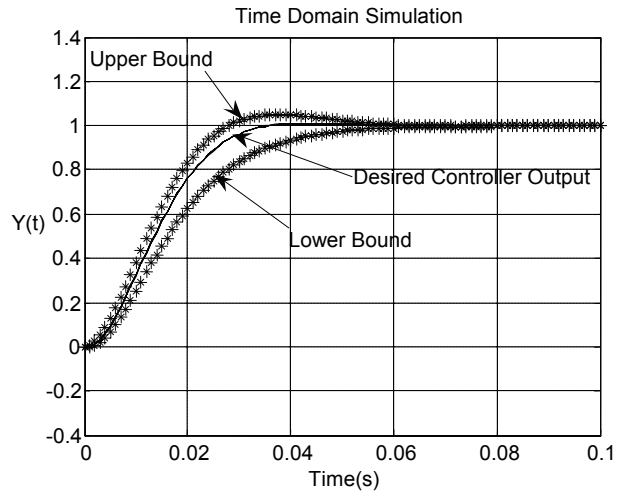

Figure 13 Step Response and Control Effort of System with G(S) and F(S) for Arm 1

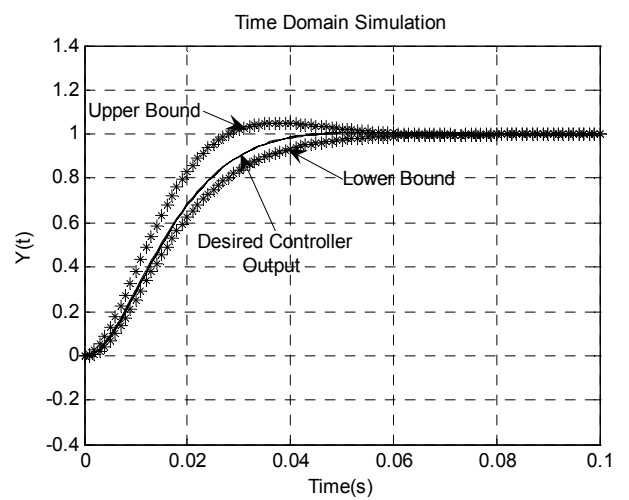

Figure 14 Step Response and Control Effort of System with G(S) and F(S) for Arm 2

\subsection{Nonlinear Analysis of Robot with Controller}

The result of tracking problem for an elliptical path is shown in Fig .15, while Fig.16 depicts the End Effecter error in Cartesian coordinate system (for $\mathrm{x} \& \mathrm{y}$ directions)

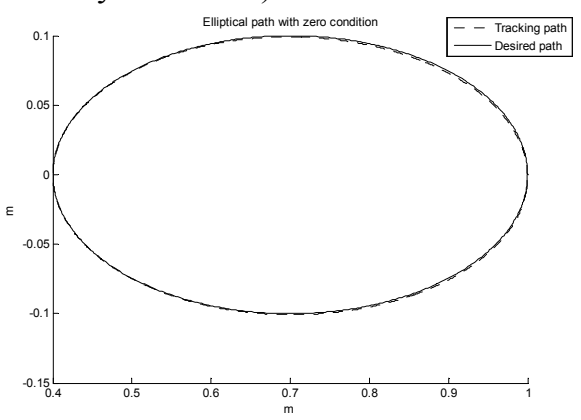

Figure 15 Tracking Problem for Elliptical Path 

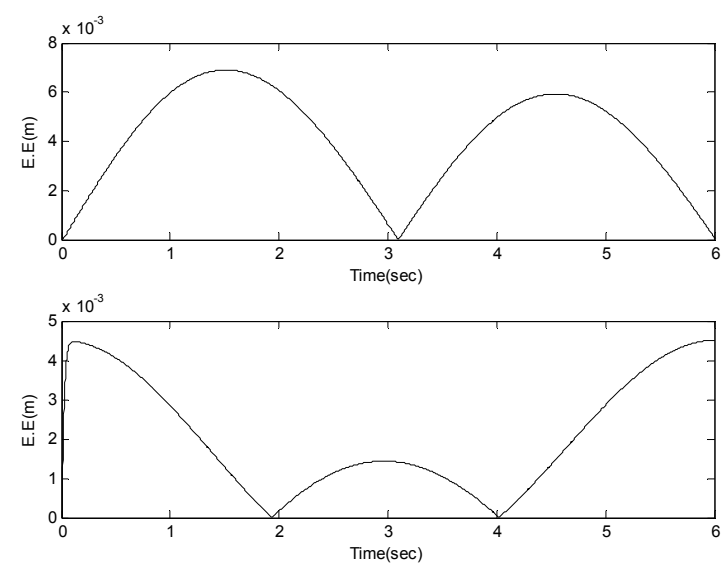

Figure 16 End Effecter Error in Cartesian Coordinate System (for X \& Y Direction)

\section{CONCLUSION}

This paper implements a new algorithm for designing optimal controller for robot arm manipulators applying QFT technique. Our research indicates that increase of accuracy in tracking problem, has direct relationship with following matters:

1) Reduction of settling time in tracking bounds for associated linear system

2) Improvement of associated linear uncertain system modeling.

3) Successful implementation of robust controller design for a two arm manipulator.

We should notice that tracking accuracy by using tighter robust performance bounds could be increased which in turn leads to an increase in the controller gain, therefore based on the design limitation suitable solutions will be obtained.

\section{REFERENCES}

[1] Luh, J. Y. S. (1983) An Anatomy of Industrial Robots and Their Controls, IEEE Trans.Automat. Conter, Vol. AC-28, No. 2, Pp.133-153.

[2] Lewis, F.L. \& et al. (1999) Robotics Mechanical Engineering Handbook .Ed. Frank Kreith .Boca Raton: CRC Press LLC.

[3] Horowitz, I M. (1991) Survey Of Quantitative Feedback Theory, Int. J. Control Journal, Vol. 33, No. 2, pp. 255, 261.

[4] Zoloas, A.C. \& Halikias, G.D. (1999) Optimal Design of PID Controllers Using the QFT Method, IEE Proc-Control Theory Appl, Vol 146, No. 6.

[5] Nataraj, P.S.V. (2002) Computation of QFT Bounds for Robust Tracking Specifications, Elsevier Science Ltd, Automatica 38 pp 327334

[6] Jing Lian, R \& Fu Lin, B. (2005) Design of a mixed fuzzy controller for multiple-input multiple-output systems, MECHATRONICS, 15 1225-1252.

[7] Moavenian, M. \& M. Gharib, (2007) linearization and robust control of scara robot, 24th International Symposium on Automation and Robotics in Construction, to be held. 